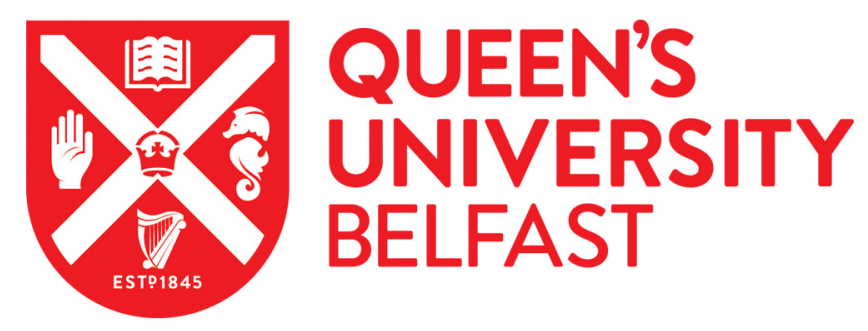

\title{
Barriers and facilitators to cooking from 'scratch' using basic or raw ingredients: A qualitative interview study
}

Lavelle, F., McGowan, L., Spence, M., Caraher, M., Raats, M. M., Hollywood, L., McDowell, D., McCloat, A., Mooney, E., \& Dean, M. (2016). Barriers and facilitators to cooking from 'scratch' using basic or raw ingredients: A qualitative interview study. Appetite, 107, 383-391. https://doi.org/10.1016/j.appet.2016.08.115

\section{Published in:}

Appetite

\section{Document Version:}

Peer reviewed version

Queen's University Belfast - Research Portal:

Link to publication record in Queen's University Belfast Research Portal

Publisher rights

(c) 2016 Elsevier Ltd. This manuscript version is made available under the CC-BY-NC-ND 4.0 license http://creativecommons.org/licenses/by$\mathrm{nc}-\mathrm{nd} / 4.0 /$ which permits distribution and reproduction for non-commercial purposes, provided the author and source are cited.

\section{General rights}

Copyright for the publications made accessible via the Queen's University Belfast Research Portal is retained by the author(s) and / or other copyright owners and it is a condition of accessing these publications that users recognise and abide by the legal requirements associated with these rights.

Take down policy

The Research Portal is Queen's institutional repository that provides access to Queen's research output. Every effort has been made to ensure that content in the Research Portal does not infringe any person's rights, or applicable UK laws. If you discover content in the Research Portal that you believe breaches copyright or violates any law, please contact openaccess@qub.ac.uk. 


\section{Barriers and facilitators to cooking from 'scratch' using basic or raw ingredients: A qualitative interview study}

Fiona Lavelle ${ }^{a}$, Laura McGowan ${ }^{a}$, Michelle Spence ${ }^{a}$, Martin Caraher ${ }^{b}$, Monique Raats ${ }^{c}$, Lynsey Hollywood ${ }^{d}$, Dawn McDowell ${ }^{d}$, Amanda McCloat ${ }^{\mathrm{e}}$, Elaine Mooneye, Moira Dean ${ }^{\mathrm{a}}$.

anstitute for Global Food Security, School of Biological Sciences, Queen's University Belfast, UK

${ }^{b}$ Centre for Food Policy, Department of Sociology, School of Arts and Social Sciences, City University London, UK

'Food, Consumer Behaviour and Health Research Centre, School of Psychology, University of Surrey, UK

${ }^{\mathrm{d} D e p a r t m e n t}$ of Hospitality and Tourism Management, Ulster Business School, Ulster University, UK eDepartment of Home Economics, St. Angela's College, Sligo, Ireland.

Email addresses:

FL: flavelle01@qub.ac.uk

LM: Laura.McGowan@qub.ac.uk

MS: m.s.spence@qub.ac.uk

MC: M.caraher@city.ac.uk

MR: M.Raats@surrey.ac.uk

LH: I.hollywood@ulster.ac.uk

DM: e10218120@uucde.ulst.ac.uk

AM: amccloat@stangelas.nuigalway.ie

EM: emooney@stangelas.nuigalway.ie

MD:moira.dean@qub.ac.uk

*Corresponding author: Dr Moira Dean, Institute for Global Food Security, School of Biological Sciences, Queen's University Belfast, Belfast BT9 5AG, UK. Phone: +44(0)28 90976561 ; fax: $+44(0) 28$ 9097 6513; e-mail: moira.dean@qub.ac.uk 
1 Background: Previous research has highlighted an ambiguity in understanding cooking related terminology and a number of barriers and facilitators to home meal

3 preparation. However, meals prepared in the home still include convenience products

4 (typically high in sugars, fats and sodium) which can have negative effects on health.

5 Therefore, this study aimed to qualitatively explore: (1) how individuals define

6 cooking from 'scratch', and (2) their barriers and facilitators to cooking with basic

7 ingredients.

8 Methods: 27 semi-structured interviews were conducted with participants (aged 18-

958 years) living on the island of Ireland, eliciting definitions of 'cooking from

10 scratch' and exploring the reasons participants cook in a particular way. The

11 interviews were professionally transcribed verbatim and Nvivo 10 was used for an 12 inductive thematic analysis.

13 Results: Our results highlighted that although cooking from 'scratch' lacks a single

14 definition, participants viewed it as optimal cooking. Barriers to cooking with raw

15 ingredients included: 1) time pressures; (2) desire to save money; (3) desire for

16 effortless meals; (4) family food preferences; and (5) effect of kitchen disasters.

17 Facilitators included: 1) desire to eat for health and well-being; (2) creative

18 inspiration; (3) ability to plan and prepare meals ahead of time; and (4) greater self-

19 efficacy in one's cooking ability.

20 Conclusions: Our findings contribute to understanding how individuals define

21 cooking from 'scratch', and barriers and facilitators to cooking with raw ingredients.

22 Interventions should focus on practical sessions to increase cooking self-efficacy;

23 highlight the importance of planning ahead and teach methods such as batch cooking 24 and freezing to facilitate cooking from scratch. 
26 Keywords: Scratch Cooking, Qualitative, Skills, Barriers, Facilitators ${ }^{1}$

\section{Introduction}

29 Over recent years, there has been concern that the culture of domestic cooking has rapidly evolved alongside broader social, environmental and technological changes to

31 the potential detriment of our diet and resulting nutritional health. Research has indicated: less time is being spent on domestic food preparation (Soliah, Walter, \& Jones, 2012; Pettinger, Holdsworth, \& Gerber, 2006), a breakdown of traditional meal patterns (Buckley, Cowan, \& McCarthy, 2007), a greater availability and consumption of high energy ultra-processed ready-made foods (typically high in sugars, fats and sodium) (Monteiro, Moubarac, Cannon, Ng, \& Popkin, 2013; Moodie et al., 2013; Monteiro, Levy, Claro, deCastro, \& Cannon, 2011; Stuckler, McKee, Ebrahim, \& Basu, 2012), and an increase in food produced and consumed outside the home environment (Mintel, 2014). Moreover, it has been suggested that whole cultures have experienced a dramatic change in their ability to select, prepare and consume food (Lang \& Caraher, 2001), with fewer and/or different cooking skills (Beck, 2007; Worsley, Wang, Wijeratne, Ismail, \& Ridley, 2015). Some researchers have also suggested a loss of the necessary skills to prepare a meal from raw ingredients (from 'scratch') (Caraher, Dixon, Lang, \& Carr-Hill, 1999). In light of this, several community diet projects have been developed to increase cooking skills among the consumer. Although such interventions lack theoretical underpinning and rigorous outcome evaluations (McGowan et al., 2015) they do have the potential to reduce overreliance on convenience foods. Indeed, previous research has shown that

\footnotetext{
${ }^{1}$ Abbreviations: NI, Northern Ireland; UK, United Kingdom; IOI, Island of Ireland; ROI, Republic of Ireland, CFS, Cooking from Scratch.
} 
those who frequently prepare a meal in the home (Wolfson \& Bleich, 2015) and use a greater number of cooking skills make healthier food choices and have a better dietary quality (Chen, Meei-Shyuan, Yu-Hung, \& Wahlqvist, 2012; McGowan et al., 2015), whereas a lack of cooking skills has been associated with increased consumption of convenience food products (van der Horst, Brunner, \& Siegrist, 2011).

To gain insights into the state of domestic meal preparation, research has investigated the perceptions of what constitutes home-cooking and the barriers and facilitators to cooking (Wolfson, Smith, Frattaroli \& Bleich, 2016a; Wolfson, Smith, Bleich \& Frattaroli, 2016b; Bowen, Elliot \& Brenton, 2014; Soliah, Walter \& Jones, 2012). Previous studies have alluded to several barriers to home meal preparation, such as parental employment (Devine et al., 2006; Jabs et al., 2007; Devine et al., 2009), lack of time (Jabs \& Devine, 2006), cost of convenience foods (Brunner, van der Horst, \& Siegrist, 2010), poor cooking skills (van der Horst et al., 2011; Stead et al., 2004), and limited food resources (Vidgen \& Gallegos, 2014). In a recent American study Wolfson et al. (2016b) found a continuum in what home-cooking meant to participants, from cooking from scratch (CFS) at one end to heating up a ready-made microwave meal at the other. Different use of terminology was debated by participants illustrating the highly individualised nature of the terms used. This lack of consensus has been previously highlighted (Short, 2006; Short, 2003). In addition, the motivators to home meal preparation have been explored using focus groups (Jones, Walter, Soliah \& Phifer, 2014), highlighting the cost effectiveness of cooking in the home, having a cooking role model, familiarity with cooking techniques and having time for the preparation, cooking and cleaning. In relation to the use of terminology, encouraging some to increase their homecooking, may encourage the use of convenience products, as Wolfson et al. (2016b) 
demonstrated that some view heating a ready-meal as home-cooking. Recent European research found that only $30 \%$ of total household food expenditure was on ‘scratch’ ingredients (Daniels \& Glorieux, 2015), with the rest being spent on convenience food and meals consumed outside the home. Another study showed that only $20 \%$ of Belgian families spend the majority of their food budget on raw or fresh ingredients, with the remainder combining fresh ingredients with some level of convenience food (Daniels, Glorieux, Minnen, van Tienoven \& Weenas, 2015). Convenience foods are normally high in saturated fat, sugars, sodium and additives (Monteiro, Moubarac, Cannon, Ng, \& Popkin, 2013; Moodie et al., 2013; Monteiro, Levy, Claro, deCastro, \& Cannon, 2011; Stuckler, McKee, Ebrahim, \& Basu, 2012), and the consumption of convenience food has been associated with overweight and obesity (van der Horst et al., 2011; Smith, McNaughton, Gall, Blizzard, Dwyer \& Venn, 2009; Malik, Willett and Hu, 2013). Further, the additives in these products have been linked to the increase in autoimmune diseases (Lerner \& Matthias, 2015). In light of this, it is important to understand what CFS means to the consumer and what barriers consumers face moving away from convenience products towards using basic or fresh ingredients in their cooking. Thus, this study explicitly explored the barriers and/or facilitators to cooking with basic or raw ingredients and how they may be different to the barriers faced in home meal preparation in general.

$$
\text { Interviews were chosen as the method of data collection as it would allow for }
$$
maximum individual clarity with the already confusing terminology, as participants within a focus group can be influenced by other dominant participants. Therefore this study qualitatively explored in a European population: (1) how individuals define cooking from 'scratch', and (2) the barriers and facilitators to cooking a meal with basic or raw ingredients. 


\section{Material and Methods}

100

101

102

103

104

105

106

107

108

\section{Participant Recruitment}

Male and female participants from the island of Ireland (IOI) were recruited via

convenience and snowball sampling with purposive acceptance to take part in a semistructured interview. Recruitment methods included announcements in the form of an email circulated to staff at a NI (Northern Ireland) and ROI (Republic of Ireland) university, interviewer contacts, and face-to-face invitations at a range of ROI community classes aimed at the unemployed. Every effort was made to include participants from different educational backgrounds and age groups, with a range of perceived cooking abilities. Of the thirty-one participants that responded with interest and completed a screening questionnaire; three did not meet the eligibility criteria (i.e. aged between 18-65 years; not involved in professional cookery; responsible for preparing at least one household meal per week) and a further one was unable to commit the necessary time. In total, 27 participants (17 females and 10 males) were interviewed (Table 1). All participants provided informed verbal consent and the study was approved by the School of Biological Sciences Ethical Committee at Queen’s University Belfast.

Table 1 Characteristics of interview participants.

\begin{tabular}{|c|c|c|c|}
\hline \multirow[t]{2}{*}{ Characteristic } & & \multicolumn{2}{|c|}{$\mathbf{N}=27$} \\
\hline & & $\mathrm{N}$ & $\%$ \\
\hline \multirow[t]{2}{*}{ Country } & Northern Ireland & 15 & 56 \\
\hline & Republic of Ireland & 12 & 44 \\
\hline \multirow[t]{3}{*}{ Age } & 18-34 years & 12 & 44 \\
\hline & 35-44 years & 5 & 19 \\
\hline & $45-58$ years & 10 & 37 \\
\hline \multirow[t]{4}{*}{ Highest Education level } & $\begin{array}{l}\text { Basic School (age 15/16, Junior } \\
\text { Cert/GCSE) }\end{array}$ & 2 & 8 \\
\hline & $\begin{array}{l}\text { Secondary School (age 17/18, Leaving } \\
\text { Cert/A Level) }\end{array}$ & 4 & 15 \\
\hline & Professional Training & 3 & 11 \\
\hline & Undergraduate level & 9 & 33 \\
\hline
\end{tabular}




\begin{tabular}{|c|c|c|c|}
\hline & Postgraduate level & 9 & 33 \\
\hline \multirow[t]{5}{*}{ Occupational Status } & Employed full-time (>30h per week) & 18 & 67 \\
\hline & Employed part-time (8-29h per week) & 3 & 11 \\
\hline & Retired & 1 & 4 \\
\hline & Student & 2 & 7 \\
\hline & Unemployed & 3 & 11 \\
\hline \multirow[t]{5}{*}{ Life Stage } & $\begin{array}{l}\text { Single/Married with children in the } \\
\text { household }\end{array}$ & 9 & 33 \\
\hline & Married with no children in household ${ }^{\mathrm{a}}$ & 4 & 15 \\
\hline & Single & 4 & 15 \\
\hline & Single with cohabitees & 6 & 22 \\
\hline & Single lives with family & 4 & 15 \\
\hline \multirow[t]{4}{*}{ Number in Household } & 1 & 4 & 15 \\
\hline & 2 & 9 & 33 \\
\hline & 3 & 8 & 30 \\
\hline & $4-6$ & 6 & 22 \\
\hline \multirow{4}{*}{$\begin{array}{l}\text { Type of ingredients used in } \\
\text { meal preparation }\end{array}$} & All Ready-made & 2 & 7 \\
\hline & $\begin{array}{l}\text { Mostly pre-prepared, some } \\
\text { fresh/basic/raw ingredients }\end{array}$ & 7 & 26 \\
\hline & $\begin{array}{l}\text { Mostly fresh/basic/raw, some pre- } \\
\text { prepared ingredients }\end{array}$ & 17 & 63 \\
\hline & All fresh/basic/raw ingredients & 1 & 4 \\
\hline \multirow{7}{*}{ Perceived Ability } & 1 & 1 & 4 \\
\hline & 2 & 2 & 7 \\
\hline & 3 & 2 & 7 \\
\hline & 4 & 7 & 26 \\
\hline & 5 & 9 & 33 \\
\hline & 6 & 2 & 7 \\
\hline & 7 & 4 & 15 \\
\hline
\end{tabular}

${ }^{\mathrm{a}}$ Includes couples with grown children no longer residing in their household.

121 Based upon a review of previous literature (McGowan et al., 2015) and a small

122 number of interviews ( $\mathrm{n}=4$ ) with experts working to improve cooking and food skills

123 (defined here as food planning, organising, shopping, budgeting), the research team

124 developed the interview questioning guide. The interview guide was piloted for

125 clarity, comprehension, reliability and timing with five individuals and refined prior

126 to implementation. The questions were designed to elicit participants perceptions

127 regarding their experiences with domestic cooking including terminology relating to

128 cooking, their motivations and barriers for cooking with basic or raw ingredients, how 
132 Table 2: Questioning route of interviewers

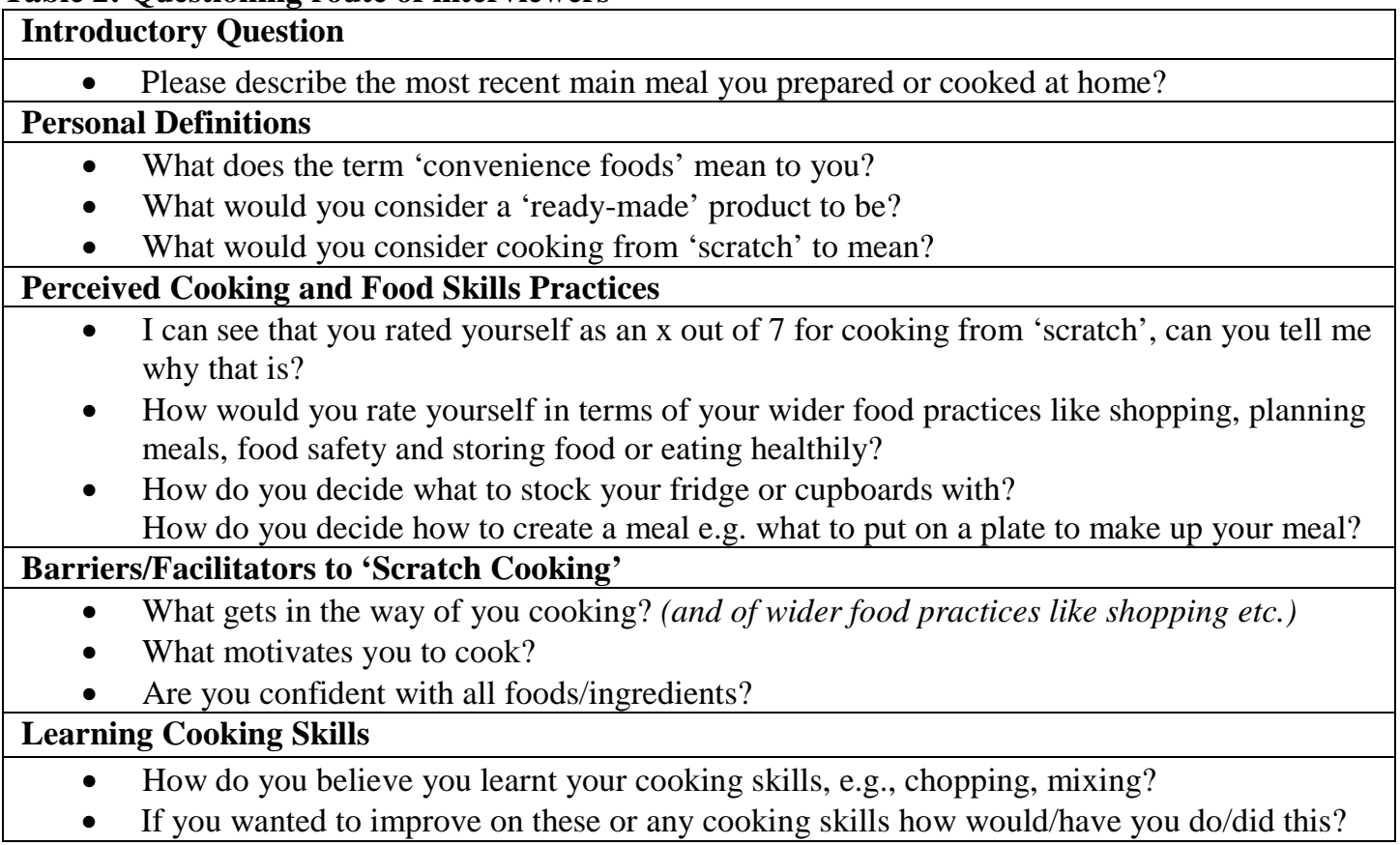

\section{Data Collection}

135 Interviews were conducted by telephone $(n=26)$ or face-to-face $(n=1)$, between

136 October and December 2014, by one of two experienced interviewers (FL; a Sport

137 and Health Scientist: and LM; a Health Psychologist) who had completed courses on

138 qualitative data collection. As an ice-breaker, participants were asked to introduce

139 themselves and describe the most recent main meal that they had prepared.

140 Interviewees were given some assurances (e.g. that there were 'no right or wrong

141 answers', their anonymity would be kept intact and they could opt out at any point)

142 before the interviewer proceeded to ask a series of guided open-ended questions

143 (Table 2). The interview concluded when all topics had been covered and no new

144 information emerged. Interviews were audio-recorded and lasted between 20 and 60

145 minutes (mean duration 36 minutes). 
147 Audio recordings were professionally transcribed verbatim, checked for precision

148 (FL, LM), and, coded thematically (Braun \& Clarke, 2006) using the qualitative 149 programme NVivo 10 (QSR International Pty Ltd, Victoria, Australia). Initially, 150 interviewers (FL, LM) independently read and coded two randomly selected 151 transcripts before jointly reaching a consensus on the validity and reliability of the 152 application of their codes to the data. This process was repeated for a further three 153 transcripts, afterwards, minor revisions were made to the terminology of some codes.

154 The remaining transcripts were then coded (FL) and independently checked for 155 coding consistency (LM) before consensus was reached (with FL). Both coders 156 agreed that data saturation had occurred as no new codes emerged from the final six 157 interviews. Subsequently, codes were grouped into potential barriers and facilitators 158 and inspected for overlap to ensure that there were clear distinctions within and 159 between barriers and facilitators. To increase intra-observer reliability, four members 160 of the research team who were experienced in qualitative data analysis (FL, LM, MS;

161 a Nutritionist and MD; a Consumer Psychologist) immersed themselves in the data 162 and critically discussed the emerging barriers and facilitators, together with their 163 interpretations. As a final step, FL, LM, MS, and MD discussed the results and 164 selected key quotes to exemplify each barrier and facilitator. Socio-demographic data 165 was summarized using IBM SPSS Statistics version 19 software (SPSS, Chicago, IL).

\section{Results}

167 The sociodemographic characteristics of the 27 participants are shown in Table 1 . To 168 ensure a wide range of cooking abilities (see Table 1), a question was included in the 169 screening questionnaire on perceived ability; “On a scale from 1 to 7 where 1 means very poor and 7 means very good, how good are you at preparing and/or cooking meals 
171 from 'scratch' at home (i.e. using basic/fresh/raw ingredients etc.)?”. Participants 172 responses ranged from 1 to 7 (Mean 4.6, SD 1.6). An overview of these participants' 173 definitions of CFS and their barriers and facilitators to cooking with raw or basic 174 ingredients is presented respectively.

\section{Perceptions of cooking from 'scratch' using basic ingredients}

176 Illustrative quotes of participants’ personal definitions of CFS can be seen in Table 3,

177 these appeared to be individualized with no clear patterns across perceived ability,

178 gender or age. Perceptions of the degree of preparation allowed for classification of a

179 meal as made from 'scratch' varied considerably. These perceptions spanned a

180 continuum from traditional understandings of the term (using raw ingredients

181 entirely) to a more inclusive modern version, which incorporated some convenience

182 products (e.g. store bought pasta). There was consensus that CFS was the "healthiest"

183 method of preparing a meal; with natural, fresh and unprocessed ingredients being

184 key components, yet, for some, the use of frozen foods (such as frozen fish fillets)

185 was also included. The degree of time and effort needed for CFS was perceived as

186 being greater than that required for convenience products, however, for many, it was

187 viewed as the goal to strive towards. 
Table 3: Illustrative quotes to demonstrate the spectrum of 'cooking from scratch' perceptions.

\begin{tabular}{|c|c|c|c|}
\hline Personal Definition & $\begin{array}{l}\text { Perceived } \\
\text { Ability }\end{array}$ & Gender & Age \\
\hline $\begin{array}{l}\text { "It means preparing sauces/condiments/everything from the raw ingredients top to bottom, so if you're making } \\
\text { a curry it means preparing the paste and chopping up all the herbs and everything, making the paste and then } \\
\text { adding the cream, doing it all completely from individual ingredients."(Participant 12) }\end{array}$ & 4 & $\mathrm{M}$ & 32 \\
\hline $\begin{array}{l}\text { "If you were making your own sauces, all like fresh food, using actual spices, I would consider made from } \\
\text { scratch meals obviously the healthiest." (Participant 27) }\end{array}$ & 1 & $F$ & 21 \\
\hline $\begin{array}{l}\text { "Once you've bought the ingredients organically, washing them and putting them together, so whether you're } \\
\text { getting a full chicken and cutting it up, whether you're getting head of broccoli and cutting it up, stuff like that, } \\
\text { same with your sauces with the least amount of stress." (Participant 25) }\end{array}$ & 5 & $\mathrm{M}$ & 24 \\
\hline $\begin{array}{l}\text { "Well something that hasn't been prepared in any way, where you're buying it fresh, well I say fresh, most of } \\
\text { the stuff I cook from scratch is frozen but I mean hasn't been treated in any way." (Participant 19) }\end{array}$ & 4 & $M$ & 57 \\
\hline $\begin{array}{l}\text { "Taking different ingredients, well for salad cooking from scratch would be washing cutting and then putting } \\
\text { oil, maybe adding olives to the greens so it doesn't involve cooking on fire but it involves preparing the } \\
\text { ingredients, like washing and cutting, for rice or spaghetti and stuff it involves boiling or put in the oven, so } \\
\text { combining different ingredients that you have manipulated some way, so taking raw ingredients and either } \\
\text { cooking them or washing, cutting, adding spices to them so that they make up a meal." (Participant 7) }\end{array}$ & 6 & $F$ & 30 \\
\hline $\begin{array}{l}\text { "It would be essentially just using basic raw ingredients, I would include the spices, not prepared sachets of } \\
\text { seasoning but possibly not grinding your own spices maybe using ready ground herbs and seasoning but not } \\
\text { using like sauces which have been pre-made or dressing and certainly preparing the vegetables." (Participant } \\
\text { 3) }\end{array}$ & 4 & $F$ & 28 \\
\hline $\begin{array}{l}\text { "Anything that can easily be made from the raw ingredients, I'd still assume like vegetable stock or chicken } \\
\text { stock or pasta to be from scratch even though in the past I have made these from flour and wheat and that but } \\
\text { I'd still kind of dub these essentials as allowing to be from scratch. For example bolognaise...I could just buy a } \\
\text { jar of Dolmio and that would be seen as cooking a meal but in my eyes it's not from scratch. From scratch is } \\
\text { the main portion of the meal should come from raw ingredients with the minimum amount of pre-made } \\
\text { ingredient, for example pasta takes quite a while to make from fresh so I use just a bag of that." (Participant 20) }\end{array}$ & 7 & $\mathrm{M}$ & 24 \\
\hline $\begin{array}{l}\text { "Cooking from scratch is doing it to what ability you feel like or how much effort you feel like putting in, if you } \\
\text { chop and prep all your veg, depending on the size of the dinner you might cheat with some things like if you're } \\
\text { making a pie, you might decide you won't use your own pastry, you'll definitely buy store bought but to me } \\
\text { that's still cooking from scratch." (Participant 2) }\end{array}$ & 5 & $F$ & 35 \\
\hline
\end{tabular}




\begin{tabular}{|c|c|c|c|}
\hline $\begin{array}{l}\text { "I suppose in the traditional meaning it is totally everything, practically growing your own, but I think times } \\
\text { have moved on. I think cooking from scratch is...it's actually washing the vegetables, getting the earth off them } \\
\text { and peeling them and cutting them yourself, it's more vegetables, maybe with chicken, I do buy whole chickens } \\
\text { but chicken fillets are easier, I tend to go for ones that are marinated so that's really convenience too, I } \\
\text { wouldn't be marinating." (Participant 14) }\end{array}$ & 3 & $\mathrm{M}$ & 51 \\
\hline $\begin{array}{l}\text { "For the curry I used mushrooms, onions, chicken fillets but I normally use a dry curry mix, Mayflower, you } \\
\text { just mix it with about } 10 \text { ounces of water and it gives you a curry sauce which actually tastes like proper } \\
\text { [bought/takeaway] Chinese curry but everything else would have been fresh ingredients." (Participant 4) }\end{array}$ & 5 & $F$ & 47 \\
\hline $\begin{array}{l}\text { "Cooking from scratch means opening the jar and putting it into the saucepan, adding my own blend of herbs } \\
\text { and spices to it, making the meatballs, I make the meatballs from scratch and then putting the pasta on." } \\
\text { (Participant 23) }\end{array}$ & 5 & $F$ & 58 \\
\hline
\end{tabular}


191 Five barriers to CFS using basic or raw ingredients were identified: (1) time pressures;

192 (2) desire to save money; (3) desire for effortless meals; (4) family food preferences; 193 and (5) effect of kitchen disasters.

\section{(1) Time pressures}

195 Almost all participants said that they were so busy that they found it difficult to cook

196 from basic or raw ingredients. The strongest time pressure appeared to come from

197 work and/or family commitments:

198 “...I don't get time to do that [cook from basic ingredients] now, because now I'm 199 a dad...it's all rush rush rush now.” (Participant 16)

200 "You've got a very limited amount of time to cook after work before you want to 201 eat, so unless you're organised you don't have any time, and if you don't have any 202 time you can't make things from scratch, it takes too long.” (Participant 12)

203 The feeling that there was not enough time, especially mid-week, was implicated 204 in the increased consumption of convenience foods:

205 "You'd probably have a little bit more processed food throughout the week just 206 due to time constraints... just less time to prepare food.” (Participant 25).

207 In addition, participants were not willing to spend the majority of their 'free' time 208 engaged in meal preparation and compromised by moving away from using basic 209 ingredients.

210 (2) Desire to save money

211 Participants, (particularly smaller households and ROI), felt that it was cheaper for 212 them to eat partially or fully prepared foods. For them, price was a major disincentive 213 to cook with basic or raw ingredients.

214 "It works out cheaper for me to buy pre-packaged dinners in Aldi." (Participant $215 \quad 23)$ 
216 Moreover, their negative attitude towards cooking with basic or raw ingredients was

217 further driven by the concern that cooking in this way would generate more food

218 waste. Reasons for this concern stemmed from the observation that more food would

219 be bought in excess and not used:

220 "I didn't realise when I was buying all those fresh stuff in the summer like veg and 221 like broccoli and chicken and that kind of stuff ... I've gotten not much in my basket 222 and this is coming to like 20 euro and I'd be afraid that I'm wasting... if I'm buying it 223 for just me I wouldn't eat a whole thing of like broccoli or whatever so then I'd nearly 224 feel like half the food would end up getting half wasted then.” (Participant 27) 225 Interestingly, some of these participants expressed their fondness for cooking in 226 general and perceived that CFS may have the greatest health benefits, however, 227 financial restraints and waste reduction strategies overpowered their positive 228 dispositions.

\section{9 (3) Desire for effortless meals}

230 For some participants, cooking from basic ingredients was viewed as a "chore” which 231 was not high on their list of priorities but cooking was seen as a necessity:

“[Cooking from scratch] is a lot of time and effort and if you're already hungry and you're standing there smelling the food and stuff, that's a nightmare so if it can't

234 be prepped and cooked within 30 to 40 minutes I won't bother and it's the same at 235 weekends.” (Participant 2)

236 Their desire for effortless meals stemmed from a 'lack of energy,' 'lack of 237 motivation' and 'laziness' and led to participants choosing convenience products or 238 consuming take-away food:

239 “There's no point in buying a whole turnip that's going to take me ages to cut into 240 and cook so I would buy the convenient packs which are already diced up and washed 241 and prepared.” (Participant 15) 
"My mood and energy levels would dictate how adventurous I would be with the meal or possibly I'd just have a takeaway.” (Participant 3)

245 Participants voiced that that their family's tastes and preferences for certain foods

246 were highly influential in determining meal choices which, in turn, governed the

247 degree to which they relied on convenience products and cooked with basic or raw

248 ingredients. Participants felt that they had 'ate what they were given' when they were

249 growing up, whereas nowadays, children have their food preferences catered for.

250 Some alluded to the food preferences of their family and their efforts to meet these in

251 order to avoid power struggles about food as a result of food refusal and selective

252 eating. An overreliance on certain foods and convenience products were often utilised 253 as an easier way to cater to the varying food preferences of each family member. For 254 example:

255 "I know what people like and what I'll get away with so I just make sure I don't 256 stray too far from that...otherwise you're in revolt.” (Participant 18)

257 “.. last night we had pizza and I didn’t want pizza but my daughter did and ...I

258 went with pizza because I knew she would eat it but with the pizza there was no extra

259 vegetables... it was quite cardboardy so there was no thought in it really.”

260 (Participant 15)

261 Family influence also restricted participants’ ability to experiment with new

262 ingredients. Even if the participant felt inspired to try something new they often felt 263 restricted:

264 "If I do something different like try something new in the house probably no one 265 would eat so it's a bit disheartening making something and no one eat it." 266 (Participant 24). 
It seemed family preferences were more influential than the desire to experiment,

268 so that meals will be eaten.

\section{(5) Effect of Kitchen Disasters}

When faced with personal cooking failures, such as strange tasting and unappealing looking dishes, participants recalled occasions in which they became discouraged and vowed not to make particular dishes from basic ingredients again. In these instances, partially or fully prepared convenience foods were often praised for their consistent taste and handiness. For example:

"I just got a basic recipe for cheesecake...my dad was sprinkling sugar on it and I didn't know why...I tried it, how disgusting it was! I was thinking they must really love me for having eaten that cheesecake... I'll not bother next time...I'll just buy one from the shop. Things like that can be a bit disheartening when you do try something and then it turns out awful...you can get food, for example, from a trusty Dolmio pack of sauce, put it in the microwave and it would of turned out nice and be ready in a minute." (Participant 27)

Personal disasters or stories from others appeared to instil fear in some participants in relation to raw ingredients and food safety and appeared to create a reluctance to use these ingredients:

"you hear about ...people [who] have been touching raw meat or something and then cooked meat and then they end up with e-coli and ..[it's] to make sure that I don’t poison anybody.” (Participant 8)

\section{Facilitators to cooking from 'scratch' using basic or raw ingredients}

Four facilitators to cooking with basic or raw ingredients were identified: (1) desire to eat for health and well-being; (2) creative inspiration; (3) ability to plan and prepare meals ahead of time; and (4) greater self-efficacy in one’s cooking ability. 


\section{(1) Desire to eat for health and well-being}

293 Within this theme, participants described how they cooked with "as much basic

294 ingredients as possible” in order to improve the health and well-being of themselves 295 and their families (e.g. “A desire to be healthy drives you to cook”). Specifically, 296 compared to convenience foods, participants viewed that preparing food from basic or 297 raw ingredients was healthier as it contained less undesirable components (i.e. fat, 298 added sugars, salt, additives and preservatives) and more fruit and vegetables. For 299 example:

300 "I've become aware...about cooking from scratch to reduce the salt content and to 301 reduce the sugar content because a lot of pre-prepared food is high in salt or sugar." 302 (Participant 14)

303 Various factors motivated participants' to eat for health and well-being, such as 304 their: nutritional knowledge; bad health (e.g. cancer); and a desire to reduce and 305 maintain body weight while avoiding the negative physical side effects of processed 306 food on the body ("reflux”, "bloating”, “migraines”, “poor athletic performance”). 307 "I know that if I cook it... natural ingredients, proper ingredients that I can eat it 308 and it doesn't irritate my stomach.” (Participant 22)

309 Some participants voiced that their motivation and behaviour towards eating more 310 healthily had increased with age:

311 “As I've got older I've noticed that sometimes processed foods and things ...doesn't always agree with me the best, so I try to do the best for my family; we're trying not to use processed food." (Participant 4)

315 Participants voiced that they often received inspirational meal ideas and recipes from

316 numerous sources which encouraged them to cook with basic or raw ingredients.

317 Recipes available through traditional (TV, newspapers, magazines, cookbooks) and 
digital media (social media, internet search engines) both clearly impacted upon the cooking habits of those who viewed them. In many cases, participants described coming across recipes "by chance" and being inspired to cook them (or a modified,

321 simplified or achievable version):

"When I'm sort of flicking through the papers at the weekend and you see a recipe and you think and you look at that and ok well actually I might not actually fancy doing that particular recipe but what they are suggesting you might do there I might bring into something which I've cooked another time." (Participant 1) media (such as webpages and websites) in contrast to print media (such as cookbooks) as it was viewed as being "handy" and "in-front" of them:

"I would look up a recipe on the internet...I would look up to see some sort of chicken dish and maybe get ideas on that BBC good food website. But yes I would tend to find myself looking up the stuff on the internet as it's easier than reading a cook book.” (Participant 6)

In addition to print/printable recipes, some participants noted getting a 'spark of inspiration' from browsing in the shops. Individuals also received inspiration from meals that they had tried in a restaurant or seen a friend make:

337 lovely I would kind of look up how to do it and maybe try and make a wee bit of it 338 myself.” (Participant 13)

\section{(3) Ability to plan and prepare meals ahead of time}

340 Within this theme participants described how organising (meals planning and grocery

341 shopping) and preparing meals ahead of time permitted them to cook with basic and

342 raw ingredients more frequently. Specifically, by batch cooking (refrigerating or 
343 freezing portion(s) for another meal) and using left-over ingredients, participants were

344 able to minimise the time and energy required to cook in this way:

345 "It's just convenience more than anything else you know if I'm going to cook I

346 might as well cook you know a big load of it so I don't have to do it every night."

347 (Participant 19)

348 "I have to sort of plan ahead...one reason why I like to do a roast on Sunday is

349 because then I know I've got leftovers and it makes it easier for me for my lunches”.

350 (Participant 8)

351 (4) Greater self-efficacy in one's cooking ability

352 Participants who self-identified as a good cook tended to cook more from basic or raw

353 ingredients and enjoy doing so:

354 "I can cook anything really, a bake or make pizzas or make bread, whatever; I

355 don’t mind, I enjoy it." (Participant 18)

356 This greater self-efficacy appeared to enable these participants to experiment more

357 with different food combinations and flavours. As a result they had a greater

358 repertoire of dishes that they were able to make and were able to take full advantage

359 of supermarket special offers:

360 "I can cook a variety of things and combine in different ways and make some

361 different tasty things.” (Participant 7)

362 "Shop smart, and don't go out with set things in your mind...such as 'I'm going to

363 cook this and this'. You can often shop off what's on offer and that can then dictate

364 your rough menu for the week so then you get a more efficient shop; bang for your

365 buck.” (Participant 20)

366 In most cases, participants who had confidence in their cooking ability attributed

367 this to earlier visual and experiential learning opportunities. Specifically, participants 
talked about how their home and/or school environment had enabled them to learn by “seeing” or by “doing”:

"I think sometimes you pick up things that you maybe would have watched your mum cook when you were a kid and you know they're there in the back of your memory and you don't realise until you're doing them yourself." (Participant 4)

"We'd be in pairs and the teacher would be at her station at the top of the room and she would just kind of be guiding us, like obviously, after in our first second or third times we kind of knew how to chop stuff properly but for the first few times she'd guide us and then she would walk away and if we needed any help she would show us.” (Participant 21)

\section{Discussion}

379 To the best of our knowledge, this is the first study to specifically explore how

380 individuals define CFS as well as the barriers and facilitators to cooking a meal with 381 basic or raw ingredients. Our rich descriptive data highlighted that CFS lacks a single 382 definition, however, participants viewed it as a goal to strive towards. Overall, nine 383 themes meaningfully hindered or enabled participants to cook with raw and basic 384 ingredients.

385 Wolfson et al (2016b) found that there was a continuum in home-cooking 386 definitions from CFS to heating a microwavable meal. Our results show that even 387 within 'scratch' cooking, participants' definitions spanned a continuum from 388 traditional understandings of the term (the entirety of the meal from basic or raw 389 ingredients) to a modern version which included some 'essential' convenience 390 products. This heterogeneity in CFS perspectives is reflective of previous literature 391 which explored meal preparation in the home environment (Wolfson et al., 2016b; Short, 2006). Wolfson et al. (2016b) concluded a definition for CFS as "all or almost 
results show that this still leaves room for ambiguity. Daniels and Glorieux (2015), also had difficulty concluding on what constituted a convenience product and created six categories, with one category being labelled other. This 'Other' category consisted

397 of food products that may be considered as staples in our current cooking and eating

398 habits such as bread and milk products, which are original convenience products. Our

399 findings show the necessity for interventions, researchers and public health

400 practitioners to clearly and consistently define what it means to cook from 'scratch' or 401 an open acknowledgement that a continuum exists and that the aim of the intervention 402 is to move people along the continuum towards the use of as many fresh ingredients 403 as possible. This is an essential first step in acquiring a more accurate understanding 404 of the relationship between cooking and healthy eating behavior in the broader 405 population.

406 Similar to results recently reported by Wolfson et al. (2016), participants viewed 407 cooking from basic and raw ingredients as the best method of cooking, 'real cooking' 408 (as mentioned by participants in Wolfson et al. 2016), and they placed a higher value 409 on this method in terms of health and nutritional quality. In the American population 410 it was accepted that although CFS had high importance, it was not seen as the norm 411 standard for cooking (Wolfson et al., 2016b), whereas, in this current sample, some 412 participants considered it quite common depending on their definition. Interestingly, 413 motivations for cooking with basic and raw ingredients did not extend beyond 414 concerns for nutritional health and well-being. This suggests that while familial 415 motivations for home-cooking (Simmons and Chapman, 2012) addressed social (i.e. 416 connecting to family and friends), cultural (i.e. retaining family culinary traditions 417 and practices and/or breaking away from them to explore new ways of eating) and 
personal factors (i.e. gaining independence through cooking skills) the main motivator

419 for CFS is primarily health. Further, Simmons and Chapman (2012) showed that the

420 ability to cook enabled the 'cook' to regulate the family food supply, whereas, our

421 results highlight a shift where the family decides the choice of food to be made rather

422 than the 'cook', similar to the findings of Soliah et al. (2012) and Dixon and Banwell

423 (2004).

424 The emergent barriers to cooking with basic and raw ingredients suggest that

425 participants require meals that are time efficient, convenient, reasonably priced, and

426 in alignment with their family’s food preferences. Some of these factors were also

427 found in Wolfson et al. (2016) with cost and time being barriers to CFS. Effort also

428 appeared to act as a barrier to cooking from scratch as mentioned in previous research

429 relating to home meal preparation (Wolfson et al., 2016b; Kaufmann, 2010;

430 Lappalainen et al., 1997; Gatley, Caraher, \& Lang, 2014). Some participants in this

431 study felt meal preparation was a necessity, and the effort needed for CFS was too

432 excessive. Daniels and colleagues (2012) also found that half the time spent cooking

433 is purely out of necessity. Interestingly, Wolfson et al. (2016) noted a link between

434 time, cost and health in home-cooking, where one of the elements was sacrificed to

435 prioritize the others. However, in relation to CFS this was not apparent. Here, those

436 that cooked from 'scratch' for health reasons did not mention time and cost although

437 time and cost were inevitably linked to other facilitators such as planning and

438 preparing ahead of time to compensate for time and cost.

439 The fear of failure associated with previous negative cooking experiences acted as

440 a barrier to some to CFS. Fearfulness has been previously noted in cooking (Stead et

441 al., 2004) but not explored in detail. The use of convenience products to overcome

442 possible negative cooking experiences appears to be a form of avoidance motivation 
443 rooted in the psychological concept of approach-avoidance. Elliot (2006) defines

444 approach-avoidance motivation as "Approach motivation may be defined as the

445 energization of behavior by, or the direction of behavior toward, positive stimuli

446 (objects, events, possibilities), whereas avoidance motivation may be defined as the

447 energization of behaviour by, or the direction of behavior away from, negative stimuli

448 (objects, events, possibilities).” Those using avoidance for survival (using

449 convenience products instead of risking a potentially disastrous meal), forgo

450 opportunities for development and improvement (learning new cooking skills) (Elliot,

451 2006).

452 Further, participants who had a greater self-efficacy in their cooking ability and

453 experienced greater inspiration from multiple sources were more inclined to cook

454 with basic and raw ingredients and have a greater repertoire of dishes that they were

455 able to make. Stead et al. (2004) also found that confident cooks had a wider

456 repertoire of recipes and had more knowledge of cooking techniques. Wriden et al.

457 (2007) also found that some of those that had an increase in cooking confidence after

458 a practical cooking intervention reported using more basic ingredients in their

459 cooking.

460 Our results collectively suggest that it is essential to provide opportunities for

461 people of all ages to gain hands-on experiences with food (i.e. cook) to both acquire

462 and perfect their food preparation skills (i.e. menu-planning and food shopping skills)

463 in order to organise and prepare a meal from basic and raw ingredients. Indeed, in this

464 study, those that self-identified as a good cook attributed their ability to cook from

465 scratch to earlier visual and experiential learning. These skills provide consumers

466 with strategies to overcome the barriers identified. Specifically, strategies such as

467 shopping more thriftily (e.g. bulk buying, taking advantage of supermarket special 
offers), batch cooking (refrigerating or freezing portion(s) for another meal), and being able to easily adjust recipes to meet family preferences all facilitate CFS. Thus, the best way to facilitate a shift from using convenience products towards basic ingredient cooking, points in the direction of teaching basic cooking and food skills. This need for practical cooking experience has been previously noted both in research and the media (Jones et al., 2012; Caraher, Seeley, Wu, \& Lloyd, 2013; Oliver, 2015). These opportunities provide an environment where people can experiment, fail and learn from their failure, and may enhance their ability to cook from scratch which in turn may boost their cooking self-efficacy. The content of these cooking interventions should focus on teaching strategies (such as ones employed by the participants in this study) to overcome barriers and emphasise the facilitators such as the health benefits of using fresh ingredients over convenience products and they should also be tailored to the individual as previously stressed by Daniels et al. (2012). Interventions should include components on: 1) the cheapness of using basic ingredients; 2) batch cooking without the use of convenience products whereby reducing the immediate effort required ; 3) enabling individuals to cook simplified versions of scratch meals they have been inspired by or their usual convenience product; and 4) family interventions allowing the children to experiment and handle new food. Children helping has been shown to increase their willingness to try new food (Nicklas et al., 2001) increasing variety in food choice. These suggestions add to the work of Short, Caraher, Lang and Halkier (Short, 2006; Caraher \& Lang, 1999; Halkier, 2009) who advocate the importance of home-cooking. Alternatively, or concurrently, hospitality and food industries should be encouraged to continue product reformulations of convenience foods to make them healthier. 
An important strength of this study was that it employed qualitative interviews to directly assess consumer perceptions about their definitions of CFS and their barriers and facilitators to cooking with basic ingredients. A few limitations deserve consideration. Firstly, despite our efforts to recruit a range of education levels, our sample where highly educated which may limit the transferability of our findings to

497 those with lower education. However, Daniels et al. (2015) found no difference in consumption of convenience products between different levels of education. It would be interesting to repeat this study in those with a lower level of education to identify additional barriers and facilitators. Furthermore, the participants volunteered without

501 any incentives for the study thus the majority of our participants indicating a level of

502 interest in food and/or cooking, although a number of participants noted that they 503 actually had no interest in cooking. Although a wide range of participants from 504 varying backgrounds were included in this study, it is worth noting that these results 505 need to be considered within the cultural context of the UK and Ireland. Participants 506 also self-rated their cooking abilities so caution must be taken considering over-

507 inflations and socially desirable responses. This was addressed, with reassurance to 508 the participants that all answers were valid and that the study was about the 509 participants' personal understandings and barriers and facilitators. Further, due to the 510 nature of the study design and the sample size, direct comparisons between age,

511 gender and abilities is not applicable, a survey of 1000 individuals on the IOI was 512 conducted as a follow up (McGowan, Pot, Stephen, Spence, Raats, Lavelle et al., 513 Under Review).

\section{Conclusions}

515 Our findings contribute to a greater understanding of how individuals define 516 cooking from 'scratch', and barriers and facilitators to cooking a meal with basic or 
raw ingredients. Interventions should focus on practical sessions to increase selfefficacy in cooking skills; highlight the importance of planning ahead and teach methods such as batch cooking with basic ingredients and freezing. More research is needed to explore these parameters in other diverse populations to fully understand

521 potential further barriers, any additional interpretations of cooking from 'scratch' and

522 to implement these strategies within interventions to evaluate their effectiveness in 523 increasing cooking with basic ingredients and in turn improving dietary quality.

\section{Competing interests}

525 The authors declare they have no competing interests.

\section{Authors' contributions}

527 MD, MS, LH, MR, MC, AM and EM were involved in the conception of the research

528 and funding acquisition; LM and FL drafted the interview schedule and conducted the 529 research; FL, LM, MS and MD performed the analysis and interpreted the data; FL 530 and LM drafted the manuscript and MD and MS edited. All authors read and 531 approved the final manuscript, and agree to be accountable for all aspects of the work.

\section{Acknowledgements}

533 The authors would like to thank all of the participants for taking the time to share

534 their views for this study. This material is based upon work supported by safefood, 535 The Food Safety Promotion Board, under Grant No. 11/2013. The Institute for Global 536 Food Security, Queen's University Belfast, 18-30 Malone Road, Belfast, gratefully 537 acknowledges the financial sponsorship of safefood in supporting FL in the 538 attendance of the ISBNPA 2015 conference to present this research.

\section{References}


540 Beck, M. E. (2007). Dinner preparation in the modern United States. British Food

541 Journal, 109(7), 531-547.

542

543 Bowen, S., Elliott, S. and Brenton, J. (2014). The joy of cooking?. Contexts, 13(3),

$544 \quad 20-25$.

545

546 Braun, V., \& Clarke, V. (2006). Using thematic analysis in psychology. Qualitative

547 research in psychology, 3(2), 77-101.

548

549 Brunner, T. A., Van der Horst, K., \& Siegrist, M. (2010). Convenience food products.

550 Drivers for consumption. Appetite, 55(3), 498-506.

551

552 Buckley, M., Cowan, C., \& McCarthy, M. (2007). The convenience food market in

553 Great Britain: Convenience food lifestyle (CFL) segments. Appetite, 49(3), 600-617.

554

555 Caraher, M., Dixon, P., Lang, T., \& Carr-Hill, R. (1999). The state of cooking in

556 England: the relationship of cooking skills to food choice. British food journal,

557 101(8), 590-609.

558

559 Caraher, M., \& Lang, T. (1999). Can't cook, won't cook: A review of cooking skills

560 and their relevance to health promotion. International Journal of Health Promotion

561 and Education, 37(3), 89-100.

562

563 Caraher, M., Seeley, A., Wu, M., \& Lloyd, S. (2013). When chefs adopt a school? An

564 evaluation of a cooking intervention in English primary schools. Appetite, 62, 50-59. 
566 Chen, R. C. Y., Lee, M. S., Chang, Y. H., \& Wahlqvist, M. L. (2012). Cooking

567 frequency may enhance survival in Taiwanese elderly. Public health nutrition, 15(07), $568 \quad 1142-1149$

569

570 Daniels, S. and Glorieux, I. (2015). Convenience, food and family lives. A socio571 typological study of household food expenditures in 21st-century Belgium. Appetite, $57294,54-61$.

574 Daniels, S., Glorieux, I., Minnen, J. and van Tienoven, T.P. (2012). More than 575 preparing a meal? Concerning the meanings of home-cooking. Appetite, 58(3), 10505761056.

578 Daniels, S., Glorieux, I., Minnen, J., van Tienoven, T.P. and Weenas, D. (2015).

579 Convenience on the menu? A typological conceptualization of family food

580 expenditures and food-related time patterns. Social science research, 51, 205-218.

581

582 Devine, C. M., Farrell, T. J., Blake, C. E., Jastran, M., Wethington, E., \& Bisogni, C.

583 A. (2009). Work conditions and the food choice coping strategies of employed 584 parents. Journal of nutrition education and behavior, 41(5), 365-370.

585

586 Devine, C. M., Jastran, M., Jabs, J., Wethington, E., Farell, T. J., \& Bisogni, C. A. 587 (2006). “A lot of sacrifices:” Work-family spillover and the food choice coping 588 strategies of low-wage employed parents. Social science \& medicine, 63(10), 25915892603. 
591 Dixon, J., \& Banwell, C. (2004). Heading the table: parenting and the junior

592 consumer. British Food Journal, 106(3), 182-193.

593

594 Elliot, A.J. (2006). The hierarchical model of approach-avoidance motivation.

595 Motivation and emotion, 30(2), 111-116.

596

597 Gatley, A., Caraher, M., \& Lang, T. (2014). A qualitative, cross cultural examination

598 of attitudes and behaviour in relation to cooking habits in France and Britain.

599 Appetite, 75, 71-81.

600

601 Halkier, B. (2009). Suitable cooking? Performances and positionings in cooking

602 practices among Danish women. Food, Culture \& Society, 12(3), 357-377.

603

604 Jabs, J., Devine, C. M., Bisogni, C. A., Farrell, T. J., Jastran, M., \& Wethington, E.

605 (2007). Trying to find the quickest way: employed mothers' constructions of time for 606 food. Journal of nutrition education and behavior, 39(1), 18-25.

607

608 Jabs, J., \& Devine, C. M. (2006). Time scarcity and food choices: an overview.

609 Appetite, 47(2), 196-204.

610

611 Jamie Oliver Food Foundation: Our Mission.

612 http://www.jamieoliverfoodfoundation.org.uk (2015). Accessed 16.07.15.

613 
614 Jones, M., Dailami, N., Weitkamp, E., Salmon, D., Kimberlee, R., Morley, A., \&

615 Orme, J. (2012). Food sustainability education as a route to healthier eating:

616 evaluation of a multi-component school programme in English primary schools.

617 Health education research, 27(3), 448-458.

618

619 Jones, S.A., Walter, J., Soliah, L. and Phifer, J.T. (2014). Perceived motivators to 620 home food preparation: Focus group findings. Journal of the Academy of Nutrition 621 and Dietetics, 114(10), 1552-1556.

623 Kaufmann, J. C. (2010). The meaning of cooking. Polity.

625 Lang, T., \& Caraher, M. (2001). Is there a culinary skills transition? Data and debate 626 from the UK about changes in cooking culture. Journal of the HEIA, 8(2), 2-14.

628 Lappalainen, R., Saba, A., Holm, L., Mykkanen, H., \& Gibney, M. J. (1997).

629 Difficulties in trying to eat healthier: descriptive analysis of perceived barriers for 630 healthy eating. European journal of clinical nutrition, 51.

632 Lerner, A. and Matthias, T. (2015). Changes in intestinal tight junction permeability 633 associated with industrial food additives explain the rising incidence of autoimmune 634 disease. Autoimmunity reviews, 14(6), 479-489.

635

636 Malik, V.S., Willett, W.C. and Hu, F.B. (2013). Global obesity: trends, risk factors 637 and policy implications. Nature Reviews Endocrinology, 9(1), 13-27. 
640 Spence, M., McCloat, A., Mooney, E. and Dean, M. "Domestic Cooking and Food

641 Skills: A Review." Critical reviews in food science and nutrition just-accepted

642 (2015): 00-00.

643

644 McGowan, L., Pot, G.K., Stephen, A.M., Spence, M., Raats, M., Lavelle, F., 645 Hollywood, L., McDowell, D., McCloat, A., Mooney, E., Caraher, M. and Dean, M. 646 (Under Review).The influence of socio-demographic, psychological and knowledge647 related variables alongside perceived cooking and food skills abilities in the 648 prediction of diet quality in adults: a nationally representative cross-sectional study.

649 International Journal of Behavioral Nutrition and Physical Activity.

650

651 Mintel. Report: 'From Grab to go: Take it Slow.' (2014).

652 www.academic.mintel.com/display/711487/?highlight Accessed 18.05.14.

653

654 Monteiro, C. A., Levy, R. B., Claro, R. M., de Castro, I. R. R., \& Cannon, G. (2011).

655 Increasing consumption of ultra-processed foods and likely impact on human health:

656 evidence from Brazil. Public health nutrition, 14(01), 5-13.

657

658 Monteiro, C. A., Moubarac, J. C., Cannon, G., Ng, S. W., \& Popkin, B. (2013). Ultra-

659 processed products are becoming dominant in the global food system. Obesity 660 reviews, 14(S2), 21-28.

661

662 Moodie, R., Stuckler, D., Monteiro, C., Sheron, N., Neal, B., Thamarangsi, T., ... \& 663 Lancet NCD Action Group. (2013). Profits and pandemics: prevention of harmful 
664 effects of tobacco, alcohol, and ultra-processed food and drink industries. The Lancet, 665 381(9867), 670-679.

666

667 Nicklas, T. A., Baranowski, T., Baranowski, J. C., Cullen, K., Rittenberry, L., \&

668 Olvera, N. (2001). Family and child-care provider influences on preschool children's

669 fruit, juice, and vegetable consumption. Nutrition reviews, 59(7), 224-235.

670

671 Oliver J. Food Revolution Day. 2015.

672 http://www.foodrevolutionday.com/campaign/\#Woy8QlrxPxoTMpf1.97 Accessed $673 \quad 16.07 .15$.

674

675 Pettinger, C., Holdsworth, M., \& Gerber, M. (2006). Meal patterns and cooking 676 practices in Southern France and Central England. Public health nutrition, 9(08), $677 \quad 1020-1026$.

678

679

Short, F. (2006). Kitchen secrets: The meaning of cooking in everyday life. Berg.

680

681 Short, F. (2003). Domestic cooking skills - what are they. Journal of the HEIA, 10(3), $682 \quad 13-22$.

683

684 Simmons, D., \& Chapman, G. E. (2012). The significance of home-cooking within

685 families. British Food Journal, 114(8), 1184-1195.

686

687 Smith, K.J., McNaughton, S.A., Gall, S.L., Blizzard, L., Dwyer, T. and Venn, A.J.

688 (2009). Takeaway food consumption and its associations with diet quality and 
711 Wolfson, J.A., Smith, K.C., Frattaroli, S. and Bleich, S.N. (2016). Public perceptions

Soliah, L. A. L., Walter, J. M., \& Jones, S. A. (2012). Benefits and barriers to healthful eating what are the consequences of decreased food preparation ability?. American Journal of Lifestyle Medicine, 6(2), 152-158.

Stead, M., Caraher, M., Wrieden, W., Longbottom, P., Valentine, K., \& Anderson, A. (2004). Confident, fearful and hopeless cooks: findings from the development of a food-skills initiative. British Food Journal, 106(4), 274-287.

Stuckler, D., McKee, M., Ebrahim, S., \& Basu, S. (2012). Manufacturing epidemics: the role of global producers in increased consumption of unhealthy commodities including processed foods, alcohol, and tobacco. PLoS Med, 9(6), e1001235.

van der Horst, K., Brunner, T. A., \& Siegrist, M. (2011). Ready-meal consumption: associations with weight status and cooking skills. Public Health Nutrition, 14(02), 239-245.

Vidgen, H. A., \& Gallegos, D. (2014). Defining food literacy and its components. Appetite, 76, 50-59.

712 of cooking and the implications for cooking behaviour in the USA. Public health 713 nutrition, 19(9), 1606-1615. 
715 Wolfson, J. A., Bleich, S. N., Smith, K. C., \& Frattaroli, S. (2016). What does

716 cooking mean to you?: Perceptions of cooking and factors related to cooking

717 behavior. Appetite, 97, 146-154.

718

719 Wolfson, J. A., \& Bleich, S. N. (2015). Is cooking at home associated with better diet 720 quality or weight-loss intention?. Public health nutrition, 18(08), 1397-1406.

721

722 Worsley, T., Wang, W. C., Wijeratne, P., Ismail, S., \& Ridley, S. (2015). Who cooks

723 from scratch and how do they prepare food?. British Food Journal, 117(2), 664-676.

724

725 Wrieden, W. L., Anderson, A. S., Longbottom, P. J., Valentine, K., Stead, M.,

726 Caraher, M., ... \& Dowler, E. (2007). The impact of a community-based food skills

727 intervention on cooking confidence, food preparation methods and dietary choices-an

728 exploratory trial. Public Health Nutrition, 10(02), 203-211. 